\title{
Intraventricular hemorrhage in a three neonates due to an arteriovenous malformation in the third ventricle
}

\author{
Nail Özdemir ${ }^{1}$, Senem Alkan Özdemir², Volkan Murat Ünal ${ }^{1}$ \\ 1 Tepecik Research and Training Hospital, Deparment of Neurosurgery, İzmir, Turkey \\ 2 Dr. Behçet Uz Children's Hospital, Department of Neonatology, İzmir, Turkey
}

Background and aims: Arteriovenous malformation (AVM) in the third ventricle rare. Three cases of neonatal intraventricular hemorrhage (IVH) secondary to rupture of AVM in the third ventricle are reported. To investigate clinical symptoms, radiological features, operative approaches, preoperative care, intraoperative findings, postoperative management and prognosis.

Methods: Three IVH from AVM were admitted to our hospital from 2014 to 2018. Documentation of the following perioperative data was sought from each neonate's record: birth weight, time of operation, method of operation, lenght of surgery, shape of lesions, lenght of hospitalization. Postoperative follow-up evaluation focused on the need for a psychomotor development. Results: The procedure was performed on one male and two females. One female was preterm. Computed tomography and magnetic resonance imaging of the brain demonstrated IVH in the third ventricle and hydrocephaly for all patients. A third ventriculostomy and aspiration for clot with endoscopy were planned. During the surgery, the AVM lesions was diffuse, large, reddish and vascular. One neonate's AVM was totally close the entrance of foramen Monroe. Therefore, third ventriculostomy wasn't performed. Coagulation was made. There was a partially obstruction for foramen Monroe of other two neonates. Coagulation, third ventriculostomy and biopsy via endoscopic approach was performed for these neonates (Figure 1 and 2). The histological diagnosis was AVM of the choroid plexus for preterm neonate.
Conclusions: Third ventricular AVM presenting with IVH is rare, since the diagnosis of this pathology is difficult and may be mistaken. If hydrocephaly is present, endoscopic procedures is appropriate.

Figure 1

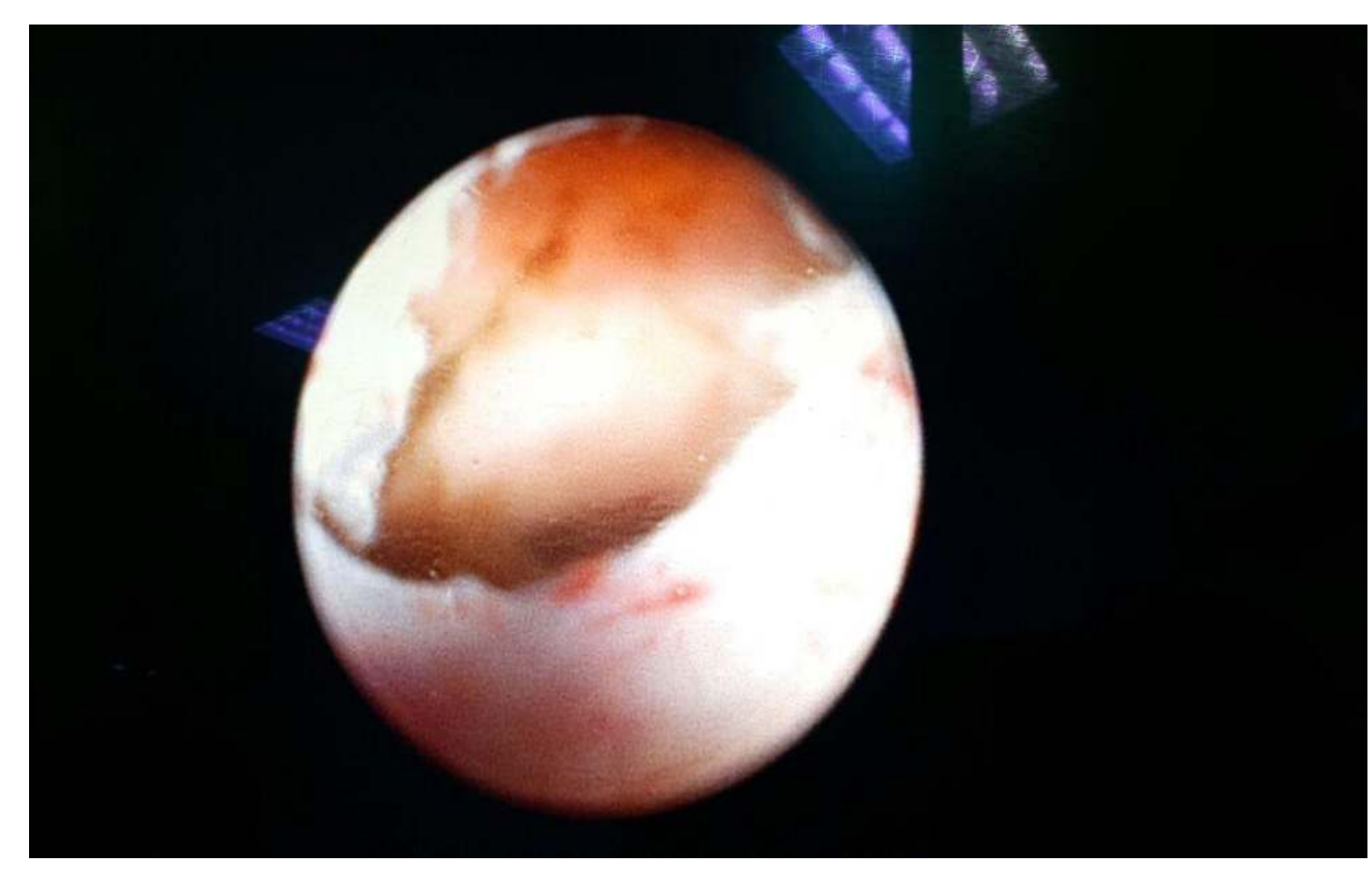

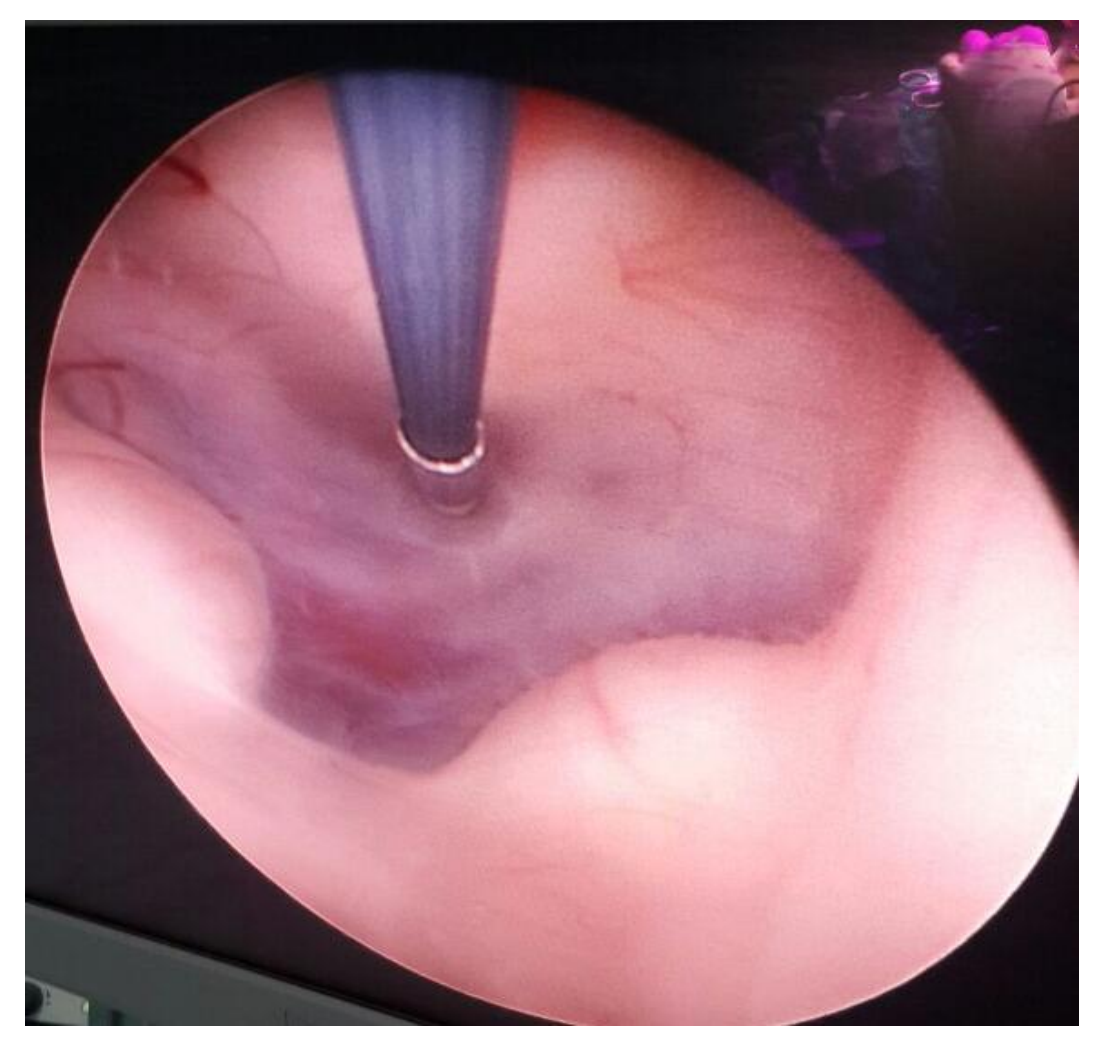

Figure 2

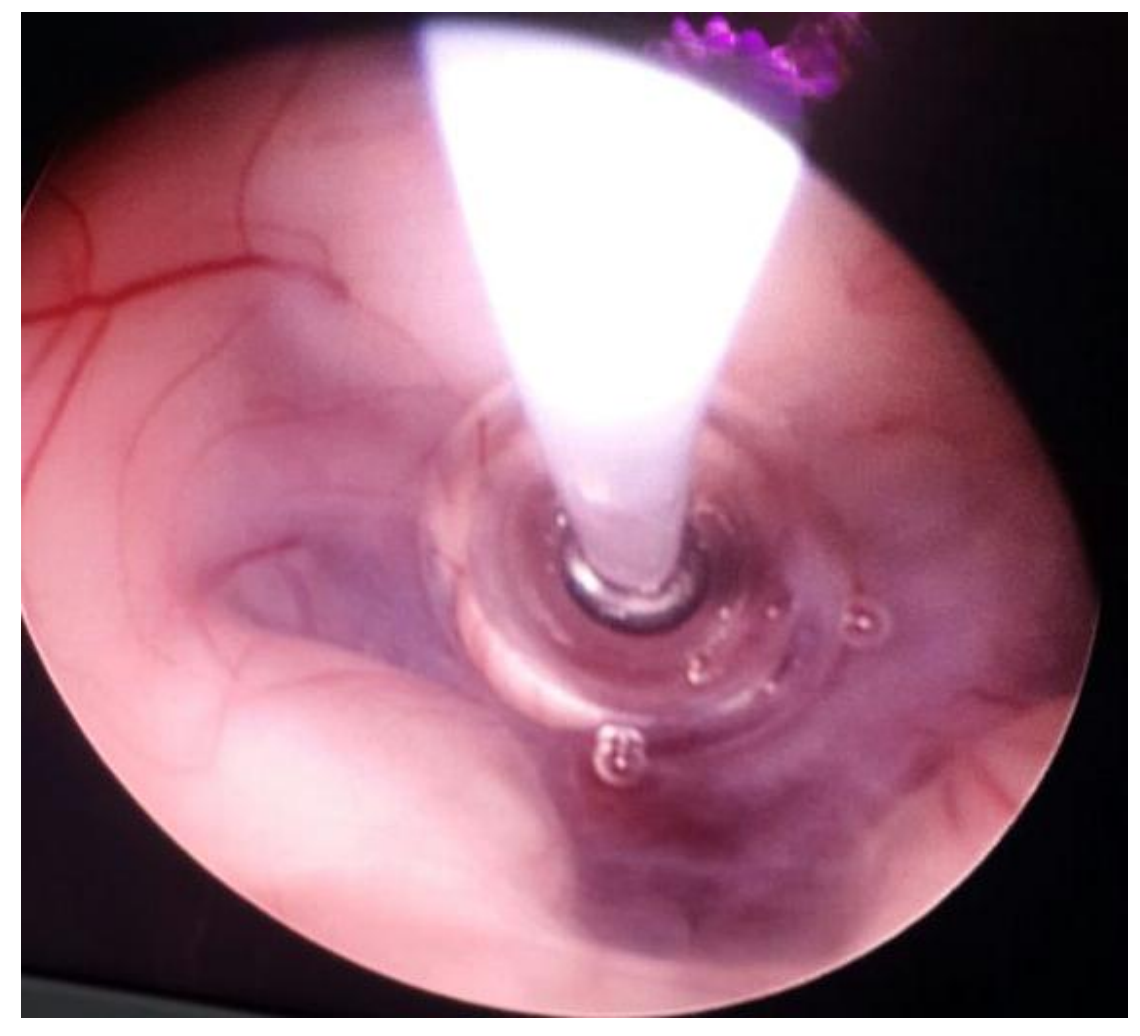

